\title{
FREIRA, MULHER, CIDADÃ: UMA ARTICULAÇÃO POSSÍVEL?
}

Teresinha Venturin*

SÍNTESE - No limiar do Terceiro Milênio do cristianismo, defrontamo-nos com novos paradigmas tanto na organização do mundo do trabalho, como nos demais espaços sociais, com repercussões bem acentuadas no campo religioso e que impõem novas demandas à formação da freira. Pretende-se, nesse estudo, fundamentar a necessidade e as possibilidades de articulação entre os elementos básicos que constituem a formação para a cidadania e competência da freira enquanto mulher e cidadã, através das ações desenvolvidas por congregações religiosas femininas.

PALAVRAS-CHAVE - formação, competência, cidadania.
ABSTRACT - On the eve of the third millenium of the Christian era, we face new paradigms both in the organization of the world of work, and in the other social spaces. This has strong repercussions in the religious field, imposing new demands to the formation of nuns. In this study we intend to show arguments for the need, as well as possibilities of articulation between the basic elements that constitute the formation towards citizenship and competence of the nun as a woman and a citizen, through the actions developed by female religious congregations.

KEY WORDS - formation, competence, citizenship.

\section{Introdução}

Este artigo é fruto de uma pesquisa relacionada com a dissertação de mestrado intitulada "Freira, mulher, cidadã: que formação?", que se propõe a verificar como vem se constituindo a formação da freira nas congregações religiosas femininas, ${ }^{1}$ frente aos desafios decorrentes do mundo contemporâneo, no Rio Grande do Sul, após 1990. Nessa oportunidade, pretendo compartilhar a revisão da literatura até então realizada e o caminho já percorrido com tal projeto de pesquisa.

A mudança veloz nos sistemas produtivos da economia configura um novo quadro social do trabalhador polifuncional, não somente de atuação nas empresas ou organizações que enfrentam desafios complexos, com novas formas de concorrência ao lado dos sistemas informatizados, mas na própria vida dos agentes

* Bacharel em Ciências Sociais (PUCRS); mestranda em Serviço Social (PUCRS) e bolsista do Conselho Nacional de Desenvolvimento Científico e Tecnológico (CNPq), Ministério da Ciência e Tecnologia.

1 Atuam no Rio Grande do Sul 5.147 religiosas, distribuidas em 77 congregações.

\begin{tabular}{|l|l|l|l|l|l|}
\hline VERITAS & Porto Alegre & v. 43 & $\mathrm{n}^{\mathbf{0}}$ especial & Dezembro 1998 & p. 71-76 \\
\hline
\end{tabular}


sociais, envolvendo todas as suas dimensões enquanto pessoa. Tal realidade é acentuada pelo intenso aprimoramento tecnológico, fundado na microeletrônica, na informática e decorrentes avanços nos meios de comunicação social. Em segundos, as notícias dão volta ao mundo, provocando uma mudança qualitativa nas relações sociais.

Essas novas demandas requerem uma reestruturação dos espaços voltados à formação da freira, não consistindo apenas numa mudança na forma de atuação e dedicação caritativa, mas também quanto à capacidade de utilizar os seus diferentes saberes e habilidades. Nesse contexto, visualizam-se novas exigências propostas pela pós-miodernidade, instigando a renovação do discurso da Igreja Católica, bem como as práticas que caracterizam as congregações religiosas.

\section{1 - O campo religioso renovando seu discurso}

A renovação do campo religioso tem acontecido em etapas, procurando acompanhar as freqüentes e profundas transformações da sociedade. Nas décadas de 60 e 70, a Igreja viveu o grande desafio de instaurar uma mudança qualitativa face às condições sociais e culturais, tendo que redefinir a noção de homem e a concepção de evangelização.

A partir do Concílio Vaticano II, a Igreja se deixa contagiar pela idéia de progresso, estimulando a renovação đas paróquias e das instituições tradicionais, propondo maior valorização da Bíblia, participação litúrgica, criação de novas formas de atuação do leigo, devido à rápida difusão das comunidades eclesiais de base e das pastorais sociais, desencadeada nos anos 70 . Surgem ainda nesse período novas formas de vida religiosa e de inserção da Igreja nos meios populares, com a opção preferencial pelos pobres e a participação de mulheres, religiosas e leigas, na ação pastoral. ${ }^{2}$

A redemocratização do país, a nova Constituição, a crise do socialismo contemporâneo e a crise econômica da América Latina transformam significativamente a sociedade brasileira atingindo as comunidades eclesiais de base, onde a corrente progressista se abrigava, provocando um grande esvaziamento dessa esfera social ${ }^{3}$ que, a exemplo da CNBB, deixa de ser o principal porta-voz dos movimentos sociais. ${ }^{4}$

O documento da Igreja rumo ao novo Milênio diz que "o grande desafio para a Igreja hoje, talvez não esteja fora, mas dentro dela mesma", a saber, o "de renovar-se frente a uma sociedade complexa e multicultural". Nas recentes diretrizes da CNBB, percebe-se a busca de uma nova linguagem nas atividades, com ênfase na formação permanente e intensiva, para os agentes de pastoral e evangelizadores, ${ }^{5}$ tendo como temáticas, a solidariedade, direitos civis, sociais e econômicos, lançando mão dos meios de comunicação social como instrumentos no processo

2 CNBB - Rumo ao novo milênio. Projeto de evangelização da Igreja no Brasil em preparação ao grande jubileu do ano 2000. São Paulo: Paulinas, documento da CNBB, n. 26, 1996, p. 22.

3 CNBB - Rumo ao novo milênio..., p. 95.

4 s/a. “CEBs perdem espaço com abertura”. Folha de São Paulo, especial. São Paulo, 25 set. 1997, p. 2.

5 CNBB - Rumo ao novo milênio.... p. 62 . 
de construção e conquista da cidadania e da democracia. À mulher cabe um papel significativo na reconstrução de alternativas à organização da sociedade, através da construção de diferentes espaços de liberdade baseados em relações mais igualitárias. ${ }^{6}$

\section{2-0 papel social da mulher e a identidade religiosa}

O acelerado processo de industrialização e modernização a partir da segunda metade do século XX, já referido anteriormente, desestabilizou os vínculos tradicionais estabelecidos entre indivíduos e grupos, abalando crenças e comportamentos estruturados há muitas décadas. A familia nuclear sofreu uma profunda transformação. As mulheres passaram a atuar massivamente no mercado de trabalho e voltaram a proclamar o direito à cidadania, denunciando as múltiplas formas da dominação patriarcal. ${ }^{7}$ Iniciam-se modificações cruciais no que concerne à identidade da mulher e ao seu papel social, ${ }^{8}$ com grande poder de influência em todos os setores sociais, o que também se registra na vida religiosa.

Se, por um lado, a Igreja Católica busca ampliar seus espaços fortalecendo o campo religioso, por outro, a mulher leiga e a freira ainda continuam caminhando à margem, na conquista de seus próprios espaços. No discurso de encerramento do Congresso Teológico no Rio de Janeiro, o Papa falou para 2.500 religiosas(os) destacando que "a luta fundamental pela dignidade do homem gira em torno da familia e da vida". Ao ser questionado sobre a ordenação de mulheres, respondeu: "Às mulheres cabe a responsabilidade de serem esposa, mãe e trabalhadora". 9

Nesse sentido, as católicas, pelo direito de decidir, numa carta aberta ao Papa, manifestam-se: "Estamos convictas da necessidade de se criar novas estruturas eciesiais que permitam a igualdade entre mulheres e homens. Queremos ver reconhecidos pela Igreja nossos direitos à decisão sobre nossos corpos e à autonomia no campo da sexualidade". ${ }^{10}$

A construção do modelo de mulher simbolizado no amor de mãe, sem sombra de egoísmo, e a abnegação sem reciprocidade formam um conjunto que compõe a imagem da maternidade, ${ }^{11}$ implicando uma desvalorização profissional, política e intelectual. Para Rago, esta desvalorização é grande porque parte do pressuposto de que a mulher em si não é nada e sua realização está no esquecer-se de si mesma, realizando-se através do êxito dos filhos e do marido, ${ }^{12} \mathrm{e}$ a freira, na doação e serviço aos outros.

6 RAGO, Margareth. "Adeus ao feminismo? Feminismo e (pós) modernidade no Brasil. Memória, história e feminismo". Cadernos AEL, Campinas, 1996, p.43.

7 Rago, op. cit., p. 31.

8 SANTOS, Claúdia R. "Misoginia e ambigüidades". Uberlândia, NEGUEM - Núcleo de Estudos de Gênero e Pesquisa sobre a Mulher, Boletim Informativo, ano 6, n. 12, $1^{\circ}$ semestre/98, p. 9.

9 "Em defesa da família. João Paulo II encerra o congresso Teológico num discurso em favor da vida". Correio do Povo, 4 out. 1997.

10 Católicas pelo direito de decidir. Carta aberta de católicas pelo direito de decidir por ocasião da visita do Papa ao Brasil.

11 RICUPERO, Rubens. “O rosto feminino de Deus". Folha de São Paulo, 4 out. 1997.

12 RAGO, Margareth. Do cabaré ao lar. A utopia da cidade disciplinar. Brasil 1890-1930. 2. ed. São Paulo: Paz e Terra, 1987, p. 65. 
Dessa forma, o papel atribuído à mulher e à freira envolve a formação de uma consciência crítica como forma e meio de desmitificar a construção de mulher e sua condição social impostas pela sociedade e ratificada pelo poder clerical. ${ }^{13}$ Nesse processo, a pessoa está envolvida no seu todo, incluindo sua própria personalidade, implicando o espaço de direito e o desenvolvimento do capital conhecimento como valor e, ao mesmo tempo, a instauração de novas disposições como um desafio inerente à formação da competência. ${ }^{14}$

\section{3 - Formação da freira, enquanto mulher e cidadã}

Durante séculos, a formação da freira permaneceu restrita à moralidade cristã, e as práticas religiosas eram alimentadas pelos princípios teóricos religiosos que norteavam a vida das freiras através das regras e normas da instituição. $O$ processo de formação visava operacionalizar ações pedagógicas voltadas à obediência e à disciplinarização, instaurando um sistema de disposições, um habitus e uma norma de agir.

Com o objetivo de formar o caráter, a principal estratégia para eficácia na instauração de uma formação integral era a ocupação de todos os tempos, em todas as ações e espaços, concebendo o trabalho como um meio de reverenciar a Deus no serviço ao próximo. ${ }^{15}$ Para Grossi, o trabalho é o fator que demarca a vida da freira, constituindo-se no "jeito de freira" e define suas relações tanto no interior como no exterior do convento. ${ }^{16}$

Organizadas em grupos, formam as comunidades, cujas origens e hábitos das pessoas são diferentes; tais comunidades não constituem a origem do estado ou coabitação. É o seu resultado. Posşuem como característica o reconhecimento da autonomia numa mesma lei, em que todas as pessoas são iguais perante a lei, e ao mesmo tempo se impõe igualmente a todas provindo sua unidade do tipo de relações, quase sempre conflituosas, ou polêmicas, que as diversas tradições coexistentes na comunidade estabelecem no decurso de uma história comum.

Porém, ao final deste milênio convivemos com um mundo pluralista em constante transformação e transição de valores, impondo-se a necessidade de um saber sistematizado em permanente formação, onde o desenvolvimento do capital conhecimento ${ }^{17}$ tornou-se fundamental. E ao mesmo tempo são desafiadas a trabalhar para a solidariedade, justiça e sobretudo na qualidade das relações humanas, propondo e repensando alternativas a uma multidão de pessoas a quem ainda faltam condições básicas de higiene, de conhecimento e para quem os direitos humanos ficam em segundo plano.

13 Rago, op. cit., p. 98

14 BOURDIEU, Pierre. Razões práticas. Sobre a teoria da ação. São Paulo: Papirus, 1996. (A palavra disposição - definida como sistema de disposição - exprime o conceito de habitus, que significa uma maneira de ser, uma predisposição. (BOURDEU, P. "Esboço de uma teoria da prática". In: ORTIZ, Renato (org.) Sociologia. São Paulo: Ática, 1983, p. 61. Coleção Grandes Cientistas Sociais).

DESAULNIERS, Julieta B. R. Trabalho: a escola do trabalhador? Tese de Doutorado. Porto Alegre: UFRGS, mar. 1995, p. 312 e 356.

16 GROSSI, Miriam. "Jeito de freira: estudo antropológico sobre a vocação feminina". Cadernos de Pesquisa, São Paulo, Fundação Carlos Chagas, n. 73, maio 1990, p. 54.

17 BOURDIEU, Pierre. Razões práticas. Sobre a teoria da ação. São Paulo: Papirus, 1996. 
É importante salientar que, para melhor apreender o processo de formação da freira e sua trajetória no espaço social entre o seu papel enquanto freira, mulher, cidadã e as instituições como agentes de formação, construímos uma metodologia associada às categorias, dimensões e indicadores, permitindo a elaboração de um questionário que se compõe de 38 questões abertas (cafeteiras), prevendo todas as respostas possiveis pela categorização, além de histórias de vida.

Desse modo, rastrear o processo de formação e a possibilidade de articulação entre freira, mulher, cidadã, implica capturar a teia complexa de relações que configuram tal processo ao se instaurar a formação para a cidadania e para a competência frente aos principais empreendimentos desencadeados pelas congregações, produzindo uma dinâmica de forma dialética que envolve, de um lado, o conflito e a contradição, e de outro, conservadorismo, inovação e transformação. ${ }^{18}$

\section{4 - Considerações finais}

Conforme o que foi exposto até aqui, a descontinuidade verificada na gênese e na estrutura das congregações religiosas femininas quanto às concepções e suas práticas relativas à formação da freira, está associada à dinâmica estrutural do campo religioso e à sua articulação, ao mesmo tempo interativa e/ou conflitiva, com a dinâmica estrutural dos demais campos.

A partir deste postulado que é central na pesquisa, delineamos hipóteses teóricas que visam articular teoria e realidade, norteando esta pesquisa e que serão demonstradas no decorrer da análise. São elas:

- o processo de globalização e o crescente surgimento de novas religióes provocaram uma revitalização do campo religioso, instigando um novo discurso expresso tanto nos seus conteúdos, como nas práticas e atividades desenvolvidas pelos agentes da Igreja Católica;

- a posição das mulheres na sociedade tem favorecido sua emancipação e a conquista de novos espaços sociais, tendendo a fortalecer o seu capital simbólico. Essas mudanças implicam novas exigências à formação da freira;

- as exigências decorrentes da globalização impõem a instauração de saberes voltados à competência, estimulando a freira na aquisição de novos conhecimentos, capacidades e habilidades, tanto nas práticas formativas dos saberes formais, quanto nos informais;

- o mundo atual exige uma administração capaz de integrar normas de trabalho distintas e de dialogar com pessoas diferentes, exigindo novas estratégias e parcerias entre os diferentes campos do espaço social, para o fortalecimento de suas lideranças;

- as congregações tendem a uma mudança nas ações e práticas de formação, promovendo o fortalecimento de seu papel enquanto agentes de formação, o que configura novos espaços de possibilidade favorecendo sua revitalização.

18 DESAULNERS, Julieta Beatriz Ramos. "Formação, competência e cidadania". Educação \& Sociedade. Campinas, Cedes, ano 18, n. 60, dez. 1997, p. 57. 
Não há dúvida de que o conhecimento é a grande força motora de construção da cidadania e da própria competência, inclusive no sentido da tomada de consciência de si mesmo e da importância dos agentes sociais para a comunidade. Nesta perspectiva, averiguar as possibilidades de instauração da competência e da cidadania na formação da freira, a partir de seus espaços de formação, propostas pelas congregações religiosas, constitui uma contribuição significativa neste momento histórico.

\section{Referências bibliográficas}

BOURDEUU, Pierre. Razōes práticas. Sobre a teoria da ação. São Paulo: Papirus, 1996.

CNBB. Rumo ao novo milênio. Projeto de evangelização da Igreja no Brasil em preparação ao grande jubileu do ano 2000. São Paulo: Paulinas, documento da CNBB, n. 26, 1996.

CORRETO do Povo, out. 1997.

DESAULNERS, Julieta B. R. Trabalho: a escola do trabalhador? Tese de Doutorado. Porto Alegre: UFRGS, março/1995.

- Formação, competência e cidadania. Educação \& Sociedade. Campinas, Cedes, ano 18, n. 60, dez. 1997.

FOLHA de São Paulo, set. e out. 1997.

GROSSI, Míriam. “Jeito de freira. Estudo antropológico sobre a vocação feminina". Cadernos de Pesquisa, Fundação Carlos Chagas, São Paulo: n. 73, maio 1990.

RAGO, Margareth. Adeus ao feminismo? Feminismo e (pós) modernidade no Brasil. Memória, História e Feminismo. Campinas: Cadernos AEL, 1996.

- Do cabaré ao lar. A utopia da cidade disciplinar. Brasil 1890-1930. 2. ed. São Paulo: Paz e Terra, 1987.

SANTOS, Claúdia R. Misoginia e ambigüidades. Uberlândia, NEGUEM - Núcleo de estudos de gênero e pesquisa sobre a mulher. Boletim Informativo, ano 6, n. 11, 1ำ semestre/98. 